\title{
GRASP LAPAROSCOPIC SURGERY BASIC SKILLS: A HIGHLY INTERACTIVE ONLINE COURSE MODEL HERE
}

\author{
Marco Frascio $^{(a)}$, Anna Siri $^{(\mathrm{b})}$, Francesca Mandolfino $^{(\mathrm{c})}$, Marco Chirico $^{(\mathrm{d})}$, Gianni Vercelli $^{(\mathrm{e})}$ \\ (a),(b),(c),(d),(e) Università degli Studi Genova \\ (a) \\ ${ }^{(\mathrm{d})}$ marco.chirico@,unige.it ${ }^{(\mathrm{e})}$ gianni.vercelli@unige.it
}

\begin{abstract}
Recent changes in surgical education and training have made the virtual learning environments more attractive than previously and have created opportunities for new instructional designs of medical curricula.

The aim of this project is to show the results of a novel online elective programme to complement existing surgical undergraduate teaching methods.

The training process was developed to enhance existing skills in the field of minimally invasive surgery among the students of the Bachelor Degree in Medicine and Surgery. Interventions were provided characterised on the one hand by the high quality of content and teaching methods, on the other hand by the strong interaction between teachers and students.

The elective course created was delivered entirely online, password-protected, and was divided into 4 modules.

30 students enrolled in the fifth and sixth-year students of the UNIGE medical schools have significantly improved their knowledge on mini-invasive surgery after the course. The evaluation results demonstrated high levels of course functionality, effectiveness of its online content and high levels of satisfaction among medical students.
\end{abstract}

Keywords: online teaching and learning model; surgical settings; evaluation model

\section{BACKGROUND}

Medical educators are facing new challenges in training tomorrow's doctors. The traditional instructor-centered education model, focused on the teacher as both authority and model, is moving to a learner-centered approach that keeps students in control of their own learning [Leung, 2002; Ruiz et al, 2006].

In the last two decades ICT -communication and information technology- have had a rapid advances with important implications and effects for education, also in the medical field [Fornaro et al., 2008; Fornaro et al., 2009; Frascio et al. 2009; Stabilini et al., 2013].

The article will go on look at the implementation of new technologies in one specific context i.e. in an online surgery education program.

Our experience started in 2008 when we organized a comparison between online and standard lessons. Given the positive results obtained by the online class, we decide to propose a completely online course.

In order to increase the number of practical and discussion environment offered to students in the traditional-curriculum scenario, and to create an online community to share knowledge on surgery, we developed and assessed a first online course for undergraduate medical students on minimally invasive surgery at the University of Genoa, Italy.

A group of students was taught online during three months on the theory of minimally invasive surgery through lessons, videos, required readings, collaborative activities using discussion board and asynchronous communication. Pre- and post-tests scores, the students' knowledge gain, their web session variables and the results of the course evaluation were used to support our study.

The primary aim of this novel study was to determine whether the use of an e-learning package about surgical topic was able to improve the knowledge and competence of medical students.

Moreover, in this article we analyzed the students' attitude towards this educational environment.

Testing a methodology for monitoring and evaluating higher-order cognitive skills in online learning was an another key element of this project.

The positive aspects and the restrictions of the model as well as our personal experiences with the implementation of an online education course are discussed.

\section{THEORETICAL PERSPECTIVES}

\subsection{Integrating e-learning into Medical education}

E-learning is a new way of teaching that the web to deliver learning contents and to promote collaborative, lerner-centerd learning and it is actually considered a well-founded complement to the traditional instructorled training, forming part of a blended-learning strategy [Davis \& al., 2007], or a valid alternative to it [ChumleyJones \& al., 2002].

In this study, "e-learning refers to the use of Internet technologies to deliver a broad array of solutions that enhance knowledge and performance" [Rosenberg, 2001].

Web-based learning is used with increasing frequency in higher-level and vocational education. 
Using e-learning, medical educators can improve educational interventions efficiency and effectiveness [Sadeghi et Al., 2014; Blissitt, 2016]. There have been several studies that have examined the effectiveness of online teaching compared to standard lecture-based approach [Cook \& al., 2005; Cook \& al., 2008; Davis \& al., 2008; Kulier \& al., 2009].

Although this teaching format offers many potential advantages, evidence supporting its use in medicine is limited. Some reviews in medical education contexts reveal that its use is highly variable among medical schools and seems to be more common in basic science modules than in internship training [Moberg, \& Whitcomb, 1999; Ward \& al., 2001; Pettersson \& Olofsson, 2015].

The perceived benefits of this learning environment include flexibility in training times, access by geographically dispersed participants, adaptability to learner styles, interactivity, and the opportunity to communicate and collaborate virtually [Harden, \& Hart, 2002; Fordis \& al., 2005]. This kind of course also allows students to go beyond the content as they learn how to search and take advantage of the huge resources of information available on web network.

The assessment of the quality of an educational process, developed in presence or at a distance is influenced both by the definition that one wants to give of the concept of "quality" as well as by the specific context in which the learning process develops [Warnecke \& Pearson, 2011; Siri \& Rui, 2015].

If we assume, as stated by Trentin [2000], that "quality" is not synonymous with "excellence", but rather indicates the operation of a continuous process to bridge the gap between the "intended effect" (what should be learned) and "the real effect" (what was learned), it is essential to establish and have in mind the aims and objectives of an educational project in order to compare them with the obtained results.

Therefore, without a doubt, a point of excellence in the training process is represented by the prediction of an integration between the design activity and the monitoring activity and assessment [Lipari, 1995; Means et al., 2009].

This perspective assumes particular significance in distance learning, where the educational process is mainly based on interactive and collaborative dynamics, which involves all members of the learning community and where the tutors are able to observe the dynamics, to monitor the whole process and to redirect it toward the desired effect.

When the interaction between service providers and users is as strong as in training, it is essential to follow a critical or "constructivist" approach, therefore sensitive to the mutual influences between the evaluator, evaluando and social actors involved in the process.

In this perspective, the importance of monitoring teaching activities and the evaluation of their efficacy, not only in terms of achieving the objectives stated in the training project, but also in function to the needs expressed by the students and the skills required by the market work.

\section{RESEARCH METHOD}

\subsection{Learning environment}

One of the most used tool in e-learning is the Learning Management System (LMS). It is a web platform that allows us to deliver information in an intuitive way using specific software for the interaction of the users.

The University of Genoa started in 2005 a new system of online teaching called "Aulaweb", an e-learning system based on the open source platform "Moodle". This system allows both students and teachers the exchange of information about topics that are uploaded on the system using forums, chats and emails. It is a user-friendly application and it enables the delivery of instructional resources, communication, and collaboration [Siri \& Rui, 2011].

In 2010, 22 online classes have been activated, with 38 teachers and 1.219 students registered.

The didactic organization of the Genoa School of Medicine (CLSMC) includes 51 teaching courses, organized in oral classes, practice activities and optional curricula activities (ADE).

The learning process of the student is evaluated using the University Didactic Credits (CFU). One CFU can be obtained after 25 hours of didactic activities.

Every student must acquire 360 CFUs during the six years of medical school in order to obtain the degree. An additional way to obtain CFUs is to attend the ADE.

A combined team of teachers from the Department of Surgery and Department of Anthropological Science of the University of Genoa has recently been built up to realize a web-based optional curricula activity that, added to the already existing web tools, can further develop and improve the University of Genoa e-learning system.

The training process was developed to enhance existing skills in the field of minimally invasive surgery among the students of the Bachelor Degree in Medicine and Surgery. Interventions were provided characterised on the one hand by the high quality of content and teaching methods, on the other hand by the strong interaction between teachers and students.

The elective course created was delivered entirely online, password-protected, and was divided into 4 modules.

The course was coached online by a main tutor; teaching assistants were assigned to help students with their field research and practice.

The course materials were presented through a series of web pages, text documents, and slides. For each topic, there were notes, objectives, assignments, selfassessment quizzes, and links to outside web resources.

\subsection{Participants}

30 students enrolled in the fifth and sixth-year students of the Genoa medical schools (academic year 20092010). Participation in the study was completely voluntary: $50 \%$ females and $50 \%$ males. The average age of the students was 25 years $( \pm 1.41 \mathrm{ST}$ DEV), with a 
minimum age of 23 years and a maximum age of $27 \mathrm{yrs}$. All the participants were full-time students.

\subsection{Learning effectiveness and satisfaction}

The entire process was monitored to control the proper development of the planned activities, to make a note of any abnormalities and to identify any changes to be made during the activity. In a wider sense, or rather an instrument of managerial control, the frequency and degree of interactivity for the students, the appreciation of assets and the orderly development of the planned activities, were checked.

Such elements have allowed the analysis of the good progress of the course according to a variety of perspectives and viewpoints, particularly those of the students, through the analysis of the user, teachers and tutors satisfaction, which is a sort of peer review and allows integration of the course feedback given by the students.

Consequently, an assessment of efficacy during the course and a conclusive one, based not only on the achievement their stated objective but also on the needs expressed by students and as a first step, was proceeded by a preliminary identification of the framework of the objectives. The framework of the objectives of the course has been translated into evaluative indicators of a quantitative character. The reconstruction of the objectives perceived by the actors occurred through the partial use of data emerging from the entry questionnaire given to the students and by the teachers considerations. It was then proceeded to analyse the congruence between the objectives of the training project and the students expectations, to then outline some aspects of the validity of the methodology adopted and the internal efficacy.

In the final assessment the tests were performed for these objectives (validity of the methodology and internal efficacy) and a test was performed with respect to the realization and to the results.

More specifically the objectives of the assessment were: - the adequacy of interventions in relation to the educational context;

- the validity of the methodology, both in relation to particular matters of method and content;

- the internal efficacy of the project, namely the degree in which the activities performed achieved the objectives foreseen;

- the external efficacy of the project, namely the degree in which the project has accomplished the needs initially defined by the students and the educational needs for the course.

The instruments for determination have been perfected since the start of the project to mid-term. Such activity has involved the monitoring group with the support of the scientific coordinator for the project. Participants have been involved in the monitoring project in the first meeting in the presence aimed at presenting the architecture of the course. The overall plan was later approved by the scientific manager.

The activities for the determination for monitoring were as follows:
$>$ Distribution of questionnaires to the participants on the training course.

In particular, the following tools have been developed, for which we briefly report the characteristics and the schedule for distribution:

a) Questionnaires for the assessment of the incoming skills of the participants. The survey, aimed at identifying professional needs and the expected skills, took place after the first meeting in person. Participants were asked to indicate in a nominative questionnaire to what extent, on a scale from 1 to 10 , they believe they have mastered each of the six skills listed in the curriculum, the extent to which they consider it useful to the profession and the extent to which they want to improve.

b) Multiple choice test designed to assess specific knowledge in the area at the start of the course

c) Questionnaire assessing the initial satisfaction of the participants. Participants were asked, always on the day of the presentation, to reflect on the expectations of the course, to express their level of satisfaction regarding the information received, the planning of the course as a whole and the usefulness of the proposal.

The questions foresaw an answering method represented by a Likert scale with uneven modality, from 1 to 5 points (avoiding the intermediate position), and a few open answers.

d) Questionnaire for the determination of satisfaction with the training activities. Participants were asked to complete an anonymous questionnaire at the end of the course in which they can express an assessment of the course, of the interaction with the teachers, of the teaching methodology, of the organization and structure. The questions foresaw an answering method represented by a Likert scale with uneven modality, from 1 to 5 points (avoiding the intermediate position), and a few open answers.

e) Questionnaire for the determination of the participants skills on exiting. The survey, aimed at identifying the expected skills, took place at the end of the course and was conducted in online modality. The participants were asked to indicate in a nominative questionnaire to what extent, on a scale from 1 to 10 , did they master each of the 6 skills listed in the teaching schedule. The goal is to get a crossed profile of the perceived competencies at the beginning of the course and those perceived at the end of the course.

f) Multiple-choice test aimed at assessing the specific knowledge in the subject acquired at the end of the course. 
$>$ Observation activities of the tutor (observation of the classroom and individual work, summarized by a report for each student).

$>$ Observation activities of the teachers (observation of the classroom and of the on-line activities, impressions summarised of the predefined outline).

$>$ Monitoring activity of the use of the virtual classroom (monitoring access to the site).

Assessment of the project is of great interest, due to its experimental nature and the need to draw insights from the experience to design other similar interventions.

Learning effectiveness was measured in terms of student learning outcomes and satisfaction.

Learning outcomes assessment was based on the student scores on the final tests and in particular on the differential between the results of the pre-test and final test.

\section{RESULTS}

30 students, on the Degree Course in Medicine (50\% females, $50 \%$ males) participated in elective educational activities, the $8 \%$ of which were registered in the $\mathrm{V}$ year of the course and the other $92 \%$ in the VI year.

During the first meeting, dedicated to the presentation of the project, with particularly regard to the contents and the teaching aids available (the virtual classroom "Aulaweb") as well as the "construction of the lecturehall pact, students were asked to reflect on the expectations regarding the proposed experience, as well as to propose potential suggestions and to express comments on the day of presentation.

The ideas that emerged from the questionnaires in terms of expectations and suggestions, which were taken into account, as mentioned, in the organization of the training course and in the predisposition of the survey instruments, are summarized below:

Expectations about the course contents:

- to improve the technical knowledge of the course according to the latest international standards

- to have a perception which is better than that which is an intervention technique on the patient who today has a much greater potential

Expectations on the innovative methodology used:

- to acquire knowledge by organizing the work according to ones schedules/availability

- $\quad$ to be able to get the same information for a course in which attendance is compulsory

- $\quad$ to have the opportunity to review the lesson again several times so as not to lose details which sometimes escape in one's presence

- $\quad$ to organize the teaching better to have more time for practical experience

- to have a smoother interaction with the teacher through forums

Comments/suggestions:

- increase the number of ADE structured on virtual classrooms

- $\quad$ improve the computerization of available courses

- $\quad$ apply this process to the examinations
- ensure that teachers are available in person for clarification.

From the above we can see that the initial expectations are very high both in terms of course objectives as well as in relation to the use of innovative teaching methods. One of the key concepts is the concept of competence, meant as the specific objective of the educational processes.

On the basis of the determination of the competencies at the beginning of the course stated by the participants in the appropriate questionnaire, a form was prepared for each student with the indication of the degree of expertise perceived for each skill, of the level of usefulness for the profession carried out and the interest for improvement. These data were then compared with the values reported in the questionnaire concerning competencies at the end of the course.

From the global analysis of the levels of competence, in particular the degree of expertise and he level of usefulness for the profession perceived by the students, it clearly emerges that the structure of the course has filled gaps in the preparation considered very important for the profession.

A summary of the perception of the participants with respect to each of the six competencies indicated in the course are shown in the chart below.

Graph n. 1: Perception skills at the beginning of the course

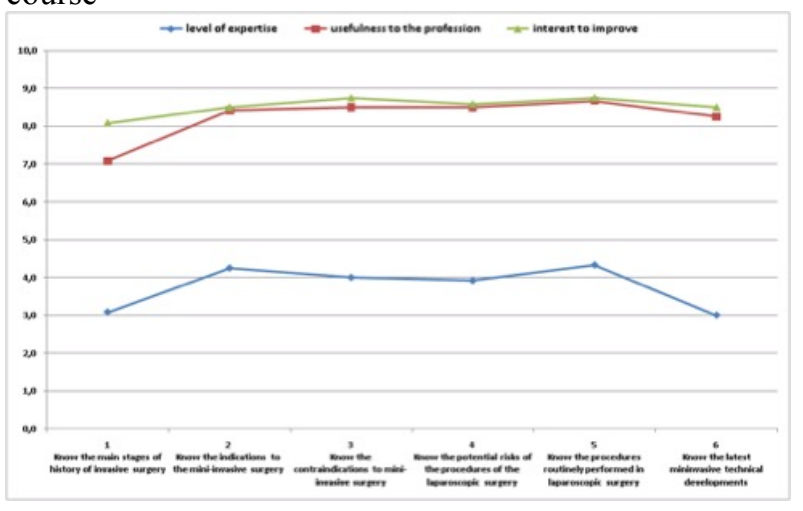

It is important to note that the initial perception on the degree of expertise for each competency at the beginning of the course is always less than the degree in which it is deemed useful for the profession and for which improvement is required/desired.

By cross-referencing the information gleaned from the incoming competency questionnaires with those outgoing, we note first of all that all of the students noticed a marked improvement in the level of expertise at the end of the course in each of the competencies declared at the beginning of the course.

The chart below, comparing the average value of the perception at the beginning and end of the course, clearly highlights the high degree of usefulness perceived by students compared to the proposed training course. 
Graph n. 2: Comparison of perception skills on entering and at the end of the course

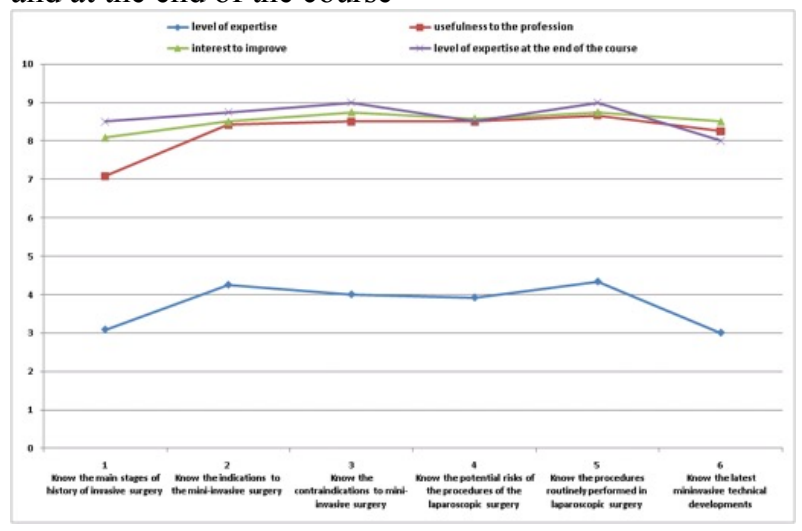

These data correspond to the results of the tests administered at the beginning of the course to assess knowledge in entry and at the end of the course to assess the degree of learning.

The overall pass rate of the enrolled students in the final online tests was $100 \%$. The average university score was $21.7( \pm 2.93 \mathrm{ST}$ DEV $)$ in the pretest and $27.3 \%( \pm 2.27$ ST DEV) in the post test. The data indicate that there was an average improvement in knowledge between the beginning and end of the course equal to $28 \%$.

Students rated all aspects of the course highly and knowledge scores increased significantly at the end of the course.

The comparison, in terms of perceived competence as well as in terms of results achieved also underlines the effectiveness of the course especially from the point of view of the theoretical reinforcement of skills already present among the recipients.

That is, the action proved to be more effective where it was able to confirm, update and sustain competencies already operative among the recipients.

By analysing the overall data obtained from the selfassessment on entering and on exiting, it is possible to advance to a reading of the results for each level of competence.

Objective 1: Know the main stages of history of invasive surgery

In this area of competence the average level of expertise indicated on entry is equal to 3; the average level for the perceived usefulness is 7 and for the interest to improve 8 .

Fifty percent (50\%) of students claim to know the stages of the history of technology at an insufficient level, $42 \%$ at level 1 and $8 \%$ at level 2 . In a barely adequate manner $25 \%$ (level 5), sufficient $17 \%$ (level 6) and only $8 \%$ have a good knowledge of the topic.

Seventy-five percent (75\%) of the students indicated that the knowledge of the topic was useful/very useful for the career, the remaining $25 \%$ thought it relatively useful. At the end of the course the average level indicated in terms of expertise is equal to 9 .
It is therefore evident that the decision to begin the ADE with a historical review of the development of the technology was greatly appreciated by the students.

Objective 2: Know the indications to the mini-invasive surgery

In this area of competence the average level of expertise indicated on entry is 4; the average level for the perceived usefulness is 8 and for the interest to improve 8.

Forty-two (42\%) of participants claimed to have a sufficient level of knowledge of the technical information at a sufficient level, 17\% a good level, the remaining $41 \%$ a level very low. All have identified the need to improve this knowledge and 64\% indicated that such knowledge is useful to the profession (levels 8, 9 and 10 ) at level 3 compared to $24 \%$ which indicates level 2.

Strong perception of improvement emerges from that stated on exiting, the average level indicated in terms of expertise is equal to 9 .

Objective 3: Know the contraindications to miniinvasive surgery

In this area of competence the average level of expertise indicated on entry is 4; the average level for the perceived usefulness is 8 and for the interest to improve 9.

Fifty percent $(50 \%)$ of the ADE participants remained below level 4 compared to $25 \%$ which indicates a sufficient level, the remaining $25 \%$ had good knowledge. Eighty-three percent $(83 \%)$ of the students are aware of the importance of knowing the contraindications of these procedures for the profession. At the end of the course the average level indicated in terms of expertise is equal to 9 .

Objective 4: Know the potential risks of the procedures of the laparoscopic surgery

In this area of competence the average level of expertise indicated on entry is 4; the average level for the perceived usefulness is 8 and for the interest to improve 9.

Fifty percent $(50 \%)$ of the participants believe they have a fair knowledge of the risks of this technique and $83 \%$ of students indicate such knowledge as being very important for the profession.

In this area there is a greater percentage of students who master this skill.

In the questionnaires on competencies on exiting a perception of great improvement in knowledge emerges, the average level is 9 .

Objective 5: Know the procedures routinely performed in laparoscopic surgery.

In this area of competence the average level of expertise indicated on entry is 4; the average level for the perceived usefulness is 9 and for the interest to improve 9. 
Forty-two (42\%) of the participants have sufficient knowledge and the remaining wholly inadequate. Ninety-two percent $(92 \%)$ consider useful the knowledge of the procedures performed routinely in laparoscopic surgery.

Also with regard to this skill, at the end of the course the average level indicated the in terms of expertise is very high, equal to 9 .

Objective 6: Know the latest mininvasive technical developments

In this area of competence the average level of expertise indicated on entry is 3; the average level for the perceived usefulness is 8 and for the interest to improve 8.

Ninety-two percent (92\%) had an insufficient level of knowledge of the latest technical developments and 75\% thought it was very useful to the profession.

In regard to this area, the degree perceived at the end of the course to improve is slightly lower and reaches an average level of 8 .

At the beginning of the course the degree of satisfaction, as evidenced by the chart below, in terms of the activities proposed as well as for the innovative methodology used, is globally very high. The information about the course objectives and the organization of training activities resulted satisfactory and comprehensive (respectively, $92 \%$ e $95 \%$ ).

When asked about the usefulness of the introduction of online learning activities within university courses, 93\% said yes and $40 \%$ specified that they did not consider it possible that courses entirely online risked being confusing. This confirms the view expressed during the first meeting in terms of expectations and suggestions. It has been shown that if teachers are available to clarify in person or actively participate in forums, answering the questions and doubts of students, the fully online mode of training cannot be the cause of confusion and therefore have little effect.

In relation to the educational objectives, to the contents, to the teaching methodologies as well as the tools used, the learners in the questionnaire given at the end of the course on the determination of appreciation of the training activities showed a very high overall mean degree of satisfaction $(85 \%)$.

However, it should be noted that, even though a higher global level of satisfaction was found, there are some comments on the planning which re-dimension the declared level of appreciation. At the end of the activity only $65 \%$ of students recorded that the course was altogether satisfactory. This finding suggests strengthening efforts to make the course clearer and emphasizing the concrete nature of the interventions, in a way which also intensifies the link between the theoretical route object of this assessment with the practical developments foreseen in other clinical training activities.
We can state, from the above, that the students have correctly interpreted the role of investigator at the end of the course, arriving at concrete proposals to implement in the field.

\section{CONCLUSIONS}

The participants have significantly improved their knowledge on mini-invasive surgery after the course. The evaluation results demonstrated high levels of course functionality, effectiveness of its online content and acceptance among medical students.

This study indicated that an online course for undergraduate students may be successfully developed and implemented also in surgery settings and the students seem to be quite supportive.

\section{Reconstruction of the objectives}

The recognition of the framework proposed by the scientific goals of the training and the investigation of the needs expressed by students, has allowed the a comparison to be built in terms of consistency with the objectives of the project submitted at the beginning of the course. In summary the objectives proposed were focused, useful to the profession and for which it caused an improvement of know-how.

Adequacy of the interventions in relation to the training context

With this specific issue in the assessment we aim to analyse the correspondence between the choices made and the characteristics of the reference setting, more specifically between the characteristics of users and the goals of intervention. In regard to this it can be noted that the analysis performed confirm the appropriateness of the selection criteria of the students, namely students belonging to the V or the VI year of the Medicine school appear to be the users who can better respond to the training schedule.

The choice of intervention and its relative use is consistent with the learning needs of students of the medical degree course.

Validity of the adopted methodology

The methodological set-up scheduled in the training project has enhanced the interactive mode and this has allowed the expression of a positive opinion on the chosen method.

The positive assessment was also affected by the usability of proposed educational activities at any time and place, considered a very important element especially in courses that require a large number of activities in person, and the opportunity to review the lessons in order to further elaborate on the topic.

External efficacy

At this level of assessment we can say that the course objectives meet the needs generated by the changes in training methods of the university educational system.

Student participation in the planning of the training has allowed the construction of common objectives and the testing of a new educational model able to integrate with the traditional models.

Internal efficacy 
The efficacy was also determined in an indirect manner on the basis of subjective assessments of learners in terms of content and learning experience. This measurement allows us to state that the quality of the operational context of the intervention is good.

Given the experimental nature of the project and the innovation of the training course the results of the survey can be summarized with the following articulations:

- $\quad$ Strong points;

- Critical points;

- Crucial points;

- Indications and suggestions for future editions

Strong points

One of the most interesting aspects of the course is represented by the prospect of integration of the in attendance training and of the online training in highly specialised courses that require a strong coordination between theoretical and practical activities.

The growth of competencies monitored through selfassessment tools, supported by positive data reported in the site of assessment of the perceived quality as well as the assessment of the degree of learning, converges in shaping a totally positive picture of the whole project system and its training program.

\section{Critical points}

The only critical aspect indicated by the participants is relative to the planning of the course, most notably in relation to the timing, which therefore requires careful consideration in the new edition.

\section{Crucial points}

According to respondents the success of the course focuses on a few significant factors, summarized as follows:

- the opportunity to attend training at times and in places which fit best with other study and work commitments;

- the opportunity to review the teaching activities to capture undertones that may escape during attendance;

- the existence of an online learning assessment that allows the students to self-assess their achievement of the objectives during the course.

\section{REFERENCES}

Blissitt AM. Blended learning versus traditional lecture in introductory nursing pathophysiology courses. J Nurs Educ. 2016;55:227-230.

Chumley-Jones HS, Dobbie A, Alford CL. Web-based learning: sound educational method or hype? A review of the evaluation literature. Acad Med. 2002; 77 (10 suppl): S86-S93.

Cook DA, Levinson AJ, Garside S, Dupras DM, Erwin PJ, Montori VM. Internet-based learning in the health professions: a meta-analysis. JAMA 2008; 300:1181-96.

Cook, D. A., D. M. Dupras, W. G. Thompson, and V. S.
Pankratz. "Web-based learning in residents' continuity clinics: A randomized, controlled trial." Academic Medicine. 2005; 80 (1): 90-97.

Davis J, Chryssafidou E, Zamora J, Davies D, Khan K, Coomarasamy A: Computer-based teaching is as good as face to face lecture-based teaching of evidence based medicine: a randomised controlled trial. BMC Med Educ 2007, 7:23.

Davis J, Crabb S, Rogers E, Zamora J, Khan KS. Computer-based teaching is as good as face to face lecture-based teaching of evidence based medicine: a randomized controlled trial. Med Teach 2008; 30:302307.

Fordis M, King JE, Ballantyne CM, Jones PH, Schneider $\mathrm{KH}$, Spann SJ, Greenberg SB, Greisinger AJ. Comparison of the instructional efficacy of Internetbased CME with live interactive CME workshops: A randomized controlled trial. JAMA. 2005; 294:1043-51.

Fornaro R, et al. Chron's disease and cancer. Annali Italiani di Chirurgia 2009; 80(2), pp. 119-125

Fornaro R, et al. Crohn's disease surgery: problems of postoperative recurrence. Chirurgia italiana; 2008, 60(6), pp. 761-781.

Frascio, M., Gervasoni, M., Lazzara, F., (...), Sguanci, M., Vercelli, G. New teaching models for the medical school of medicine. Comparison between oral an online classes. The experience of the Genoa school of medicine. Journal of E-Learning and Knowledge Society 2009 5(3), pp. 43-48

Harden RM, Hart IR. An international virtual medical school (IVIMEDS): the future for medical education? Med Teacher. 2002; 24:261-7.

Kulier R, Coppus S, Zamora J, et al. The effectiveness of a clinically integrated e-learning course in evidencebased medicine: A cluster randomised controlled trial. BMC Medical Education 2009; 9:21.

Leung, W.C.. Competency based medical training: review. BMJ. 2002; 325: 693-696.

Lipari, D. Progettazione e valutazione nei processi formativi, Edizioni Lavoro, Roma, 1995.

Means, B., Toyama, Y., Murphy, R., Bakia, M., Jones, K.. Evaluation of Evidence-Based Practices in Online Learning: A Meta-Analysis and Review of Online Learning Studies, U.S. Department of Education Office of Planning, Evaluation, and Policy Development, Washington, D.C., 2009. Policy and Program Studies Service. 
Moberg TF, Whitcomb ME. Educational technology to facilitate medical students' learning: background paper 2 of the medical school objectives project. Acad Med. 1999; 74: 1146-50.

Rosenberg M. E-Learning: Strategies for Delivering Knowledge in the Digital Age. New York: McGraw-Hill, 2001.

Ruiz, J., Mintzer, M.J., Leipzig, R.M.. The Impact of ELearning in Medical Education. Academic Medicine 2006; 81(3): 207-212.

Siri A, Rui M. (2015). Distance education for health professions' students. International Conference on New Horizons in Education, INTE 2014, 25-27 June 2014, Paris, France. Procedia - Social and Behavioral Sciences, Volume 174, 12 February 2015, pp. 730-738.

Siri A, Rui M (2011). A teachers' training program at the University of Genoa. In: "E-learning innovative models for the integration of education, technology and research. 5th GUIDE International Conference Proceedings". Roma, Italy, 18-19 Novembre 2011, Roma: Guide Association, p. 1-10, ISBN/ISSN: 978-88-97772-00-2.

Stabilini C., Bracale U., Pignata G., Frascio M. Lazzara F., Gianetta E. Laparoscopic bridging vs. anatomic open reconstruction for midline abdominal hernia mesh repair [LABOR]: Single-blinded, multicenter, randomized, controlled trial on long-term functional results. 2013 Trials 14(1), 357.

Trentin G., The Quality-Interactivity Relationship in Distance Education, Educational Technology. 2000; 40, 1, 17-27.

Ward JP, Gordon J, Field MJ, Lehmann HP. Communication and information technology in medical education. Lancet. 2001; 357: 792-96.

Warnecke E, Pearson S. Medical students' perceptions of using e-learning to enhance the acquisition of consulting skills. Australas Med J. 2011;4:300-307.

Sadeghi R, Sedaghat MM, Sha Ahmadi F. Comparison of the effect of lecture and blended teaching methods on students' learning and satisfaction. J Adv Med Educ Prof. 2014;2:146-150.

Pettersson F, Olofsson A. Implementing distance teaching at a large scale in medical education: a struggle between dominant and non-dominant teaching activities. Educ Doc Inf s. 2015;20:359-80. 